\title{
Acute respiratory distress syndrome, metabolic acidosis, and respiratory acidosis associated with citalopram overdose
}

\author{
Hawa Edriss MD, Marie Pfarr BA
}

\begin{abstract}
We report a 53-year-old man who ingested $2400 \mathrm{mg}$ of citalopram and presented to the emergency department three hours post-ingestion with altered mental status, somnolence, and a blood pressure of $67 / 45 \mathrm{mmHg}$. He failed to respond to three boluses of normal saline (1000 $\mathrm{ml}$ each) and required vasopressors. The patient developed serotonin syndrome with hyper-reflexia, rigidity, and ankle myoclonus. He had a tonic-clonic seizure in the ER requiring intravenous lorazepam and phenytoin. An ECG showed QT prolongation. Chest x-ray on presentation was normal. Within 32 hours the patient developed acute respiratory distress, hypoxemia, a wide $\mathrm{A}$-a gradient, $\mathrm{PaO} 2 / \mathrm{FiO} 2<$ 200 , and chest $x$-ray changes compatible with acute respiratory distress syndrome (ARDS). He had normal central venous pressures, normal cardiac biomarkers, normal systolic and diastolic functions on echocardiography, and no acute ST/T wave changes. His $A B G$ showed a metabolic acidosis and a respiratory acidosis. The patient required intubation and ventilation. Citalopram has been associated with seizures and ECG abnormalities after overdoses. The respiratory complications and metabolic acidosis have been reported only a few times in the literature. We are reporting the second case of ARDS and the fifth case of metabolic acidosis due to citalopram overdose and suggest that the metabolic acidemia is explained by propionic acid. The respiratory acidosis seen in this patient has not been reported previously.
\end{abstract}

Key words: Citalopram toxicity, acute respiratory distress syndrome, metabolic acidosis, respiratory acidosis, propionic acid

\section{INTRODUCTION}

Citalopram is a commonly used selective serotonin reuptake inhibitor (SSRI) for psychiatric indications, including depression, anxiety, and obsessive-compulsive disorder. ${ }^{1}$ Some commonly reported adverse effects with overdoses include CNS depression, seizures, QT prolongation and arrhythmias, and serotonin syndrome. ${ }^{2}$ There are limited data on respiratory complications from citalopram overdoses.

Corresponding author: Hawa Edriss MD

Contact Information: hawa.edriss@ttuhsc.edu

DOI: 10.12746/swrccc2014.0205.058
We report a case of citalopram overdose with noncardiogenic pulmonary edema. Additionally, this is the fifth reported case with metabolic acidosis associated with a citalopram overdose.

\section{Case Presenttion}

A 53-year-old African-American man with a history of hypertension, depression, and drug abuse was brought to the emergency room by EMS due to altered mental status. The patient reportedly fell in the bathroom (witnessed by his girlfriend) and sustained a $2 \mathrm{~cm}$ laceration to his left upper eyelid. During trans- 
fer his Glasgow Coma Score (GCS) was 15 according to EMS assessment; however, en route he became more confused and somnolent and had a seizure that lasted 30 seconds. The patient was given $1 \mathrm{mg}$ of lorazepam, $1000 \mathrm{mg}$ of phenytoin, and activated charcoal in the ER. He was unresponsive to questions, and information about a possible overdose was unattainable.

On arrival, his blood pressure was 67/45 $\mathrm{mmHg}$, and he received 3 liters of normal saline in ER. His blood pressure remained low; he required vasopressors (norepinephrine and dopamine). The patient's respiratory rate was 22 breaths/min, oxygen saturation $89 \%$, HR 77 beats/min, and temperature $97 \%{ }^{\circ} \mathrm{F}$. The patient required $\mathrm{O}_{2}$ supplementation by nasal cannula $\left(\mathrm{FiO}_{2} 32 \%\right)$. His physical examination revealed a marked decrease in level of consciousness and somnolence; his GCS was 7 . The patient opened his eyes only to painful stimuli, he made incomprehensible sounds, and his motor assessment showed flexion to painful stimuli. The patient's muscular tone was increased, and his reflexes were increased $(+3)$ throughout with positive ankle myoclonus. The pulmonary, cardiovascular, and abdominal examinations were normal.

Laboratory studies: white blood count $8.1 \mathrm{k} /$ $\mu \mathrm{L}$, hemoglobin $16.2 \mathrm{~g} / \mathrm{dL}$, platelet $149 \mathrm{k} / \mu \mathrm{L}$, serum glucose $115 \mathrm{mg} / \mathrm{dl}$, serum sodium $143 \mathrm{mmol} / \mathrm{L}$, serum potassium $3.6 \mathrm{mmol} / \mathrm{L}$, chloride level 102 $\mathrm{mmol} / \mathrm{L}$, serum bicarbonate (total CO2) $14 \mathrm{mmol} / \mathrm{L}$, serum creatinine $1.3 \mathrm{mg} / \mathrm{dl}$, BUN $13 \mathrm{mg} / \mathrm{dl}$, serum osmolality 295 (275-295 mOsmol/kg), anion gap 27, serum magnesium $2.1 \mathrm{mg} / \mathrm{dl}$, lactic acid $2.2 \mathrm{mmol} / \mathrm{L}$ (0.7-2.1), CK 166 units/L (26-308), CKMB 2.7 ng/ml, troponin $\mathrm{T}<0.01 \mathrm{ng} / \mathrm{ml} \times 3$, urinalysis unremarkable, alcohol level negative, urine drug screen positive for cocaine, acetaminophen levels $<15 \mu \mathrm{g} / \mathrm{ml} \times 2(15-30)$, salicylate $<0.3 \mathrm{mg} / \mathrm{dl}(0-20)$, ethylene glycol< $10 \mu \mathrm{g} /$ $\mathrm{ml}(<10)$. His initial arterial blood gases revealed $\mathrm{pH}-$ 7.27, $\mathrm{PaCO}_{2^{-}} 47.6 \mathrm{mmHg}, \mathrm{PaO}_{2}-63.2 \mathrm{mmHg}$, and HCO3-21.4 mmol/L. His delta ratio was 1.5 , and the expected $\mathrm{PaCO}_{2}$ was $27-31 \mathrm{mmHg}$. The $\mathrm{PaO}_{2} / \mathrm{FiO}_{2}$ was 197.5, and the A-a oxygen gradient was 105 .

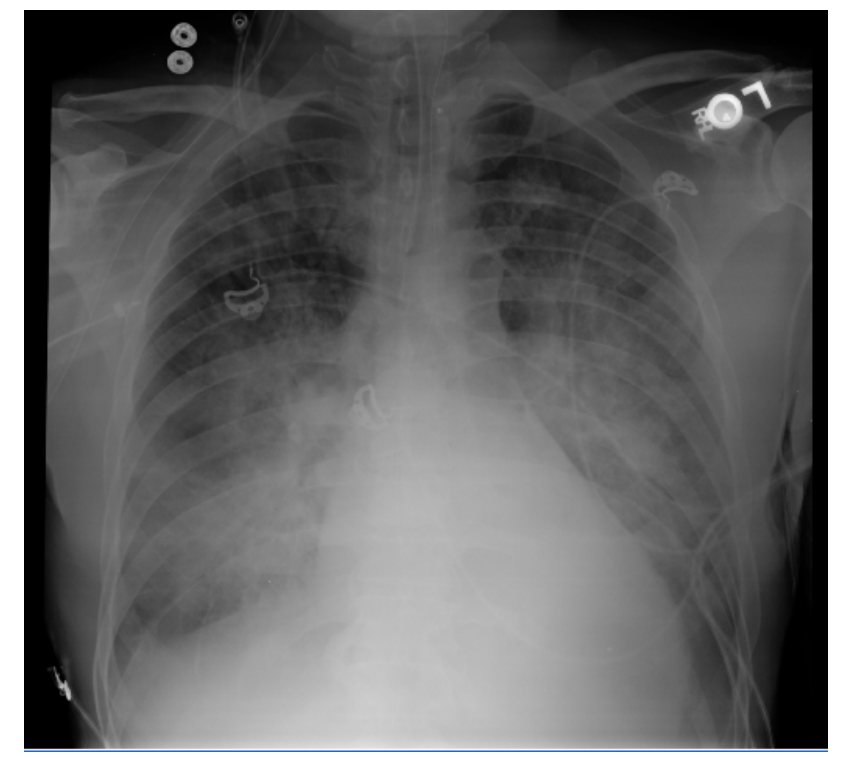

Figure 1. An A-P portable chest x-ray reveals bilateral alveolar infiltrates consistent with noncardiogenic pulmonary edema.

Chest $\mathrm{x}$-ray on admission showed normal lung fields. Computed tomography (CT) of the head revealed no acute infarcts, bleeding, mass effect, or bony abnormalities. A CT scan of the cervical spine revealed no fractures or dislocations. His ECG showed HR 77, RR interval 778 ms, QT 408 ms, QTc $462 \mathrm{~ms}$ (normal range of $440 \mathrm{~ms}$ or less in men), and no acute ST/T wave changes. Transthoracic echocardiography showed a normal EF (50-55\%), normal left ventricular wall thickness, normal diastolic function, no regional wall motion abnormalities, and normal valves except for pulmonary valve regurgitation with moderate pulmonary hypertension. By the next day, his level of consciousness had improved, and he was able to open his eyes to verbal stimuli. He was off vasopressors. However, seven hours later the patient developed acute respiratory distress. His respiratory rate was 33 breaths/minute, $\mathrm{O}_{2}$ saturation was $87 \%$ on $100 \% \mathrm{O}_{2}$ by face-mask, blood pressure was $139 / 83 \mathrm{mmHg}$, and heart rate was 116 beats/minute. He was intubated for mechanical ventilation. Chest x-ray showed diffuse bilateral opacities consistent with pulmonary edema (Figure). He had a widened A-a oxygen gradient and $a \mathrm{PaO}_{2} / \mathrm{FiO}_{2}$ ratio $<200$. 
Myocardial infarction was ruled out; his blood pressure was within normal range. The patient was able to be extubated successfully after 34 hours of ventilatory support. A more detailed history after the patient was extubated revealed that the patient had taken 60 tablets of citalopram (40 mg each) and 15 pills of hydroxyzine (25 mg each) three hours prior to the ER arrival. He also admitted "snuffing" cocaine for more than eight months, and he used cocaine the day of admission.

\section{Discussion}

Citalopram is a selective and potent inhibitor of neuronal serotonin reuptake and increases the level of serotonin in the synaptic clefts in the central nervous system. The typical therapeutic dosage of citalopram is $20-60 \mathrm{mg} / \mathrm{d}^{1}$. Side effects with therapeutic dosing include nausea, vomiting, constipation, diarrhea, mild systemic vasodilation with hypotension, and somnolence. ${ }^{1-3}$ Mild symptoms (dizziness, drowsiness, nausea) occur after the ingestion of higher doses. ${ }^{4}$ Patients can present with seizures within a few hours after ingestion and cardiac toxicity (prolongation of QT interval, arrhythmias, and bradycardia) within 8-10 hours after an overdose of more than $600 \mathrm{mg}$. Serious, life-threatening presentations, such as generalized convulsions, rhabdomyolysis, and toxic serotonin syndrome, can occur after ingestion of more than $1900 \mathrm{mg}$. In the serotonin syndrome patients develop tremors, hyperpyrexia, increased rigidity, hypertension, and seizures. ${ }^{2}$ More complex syndromes, including seizures, acute kidney injury with oliguria, and adult respiratory distress syndrome (ARDS), have developed after the ingestion of 3,000 $\mathrm{mg}$ of citalopram. ${ }^{6}$ A consistently fatal dose is uncertain, and one patient has survived the ingestion of $5200 \mathrm{mg}^{7}$

The patient in our case reported taking 2400 $\mathrm{mg}$ of citalopram and $375 \mathrm{mg}$ of hydroxyzine. He developed severe citalopram toxicity based on the poisoning severity score of the European Association of Poison Centres and Clinical Toxicologists in which the severity of the symptoms are classified as minor, moderate, and severe. Severe symptoms include a GCS of 3 to 8, severe arrhythmia, aspiration pneumonia, and respiratory failure requiring intubation. Toxicity is considered severe if at least one severe symptom is present. ${ }^{8,9}$ Our patient had a GCS score of 7 and required intubation. His overdose also included hydroxyzine and possibly cocaine. Hydroxyzine is a first generation histamine-1 receptor blocker, and side effects include anticholinergic effects, such as dry mouth, urinary retention, and blurred vision. ${ }^{1}$ When ingested in an overdose, hydroxyzine can cause dyskinesia, dystonic reactions, tardive dyskinesia, tremor, seizures, hypotension, and coma. Our patient also took cocaine which is a sympathomimetic that blocks the reuptake of norepinephrine, dopamine, and serotonin and causes CNS stimulation and peripheral vasoconstriction. ${ }^{10}$ These side effects increase blood pressure and heart rate and induce arrhythmias which did not occur in this patient.

Within thirty-two hours our patient had developed acute respiratory distress, hypoxemia $\left(\mathrm{PaO}_{2} \mathrm{I}\right.$ $\mathrm{FiO}_{2}$ of $<200$, increased alveolar-arterial oxygen gradient), diffuse bilateral opacities on chest x-ray, and no sign of cardiogenic pulmonary edema (normal central venous pressure, normal left ventricular systolic function on echocardiography, no acute ST/T wave changes and normal cardiac biomarkers). These clinical and radiographic features were consistent with ARDS. ${ }^{11}$ This syndrome has been described after tricyclic antidepressants, but only one case has been reported after citalopram overdose in a 45-year-old man ingested $3000 \mathrm{mg}$ of citalopram and developed ARDS and renal failure. ${ }^{6,12}$ The mechanism of acute lung injury may be secondary to direct effects of serotonin on endothelial and/or epithelial cells causing increased permeability of the alveolar-capillary barrier. $^{12,13}$

Our patient also developed acid base disorders with both metabolic and respiratory acidosis. There have been four cases of metabolic acidosis reported in the literature due to citalopram overdose in humans, and we are reporting the fifth case. ${ }^{2,14}$ Grundmar et al reported two cases of non-fatal citalopram overdose (1680 mg and $5200 \mathrm{mg}$ ) with metabolic aci- 
dosis. ${ }^{14}$ Jimmick et al also reported a case of metabolic acidosis due to citalopram overdose in 2008, and Bin Salih et al reported a patient with metabolic acidosis and generalized seizures in 2010 . $^{2,15}$ Citalopram is metabolized to $\mathrm{N}$-desmethylcitalopram, didesmethylcitalopram, and propionic acid (molecular formula: $\mathrm{C}_{3} \mathrm{H}_{6} \mathrm{O}_{2}$, molecular mass: $74.08 \mathrm{~g} \mathrm{~mol}^{-1}$, acidity/pKa: 4.87). CYP2C19 catalyzes the formation of propionic acid from citalopram, and this pathway accounts for about one-third of the metabolism of citalopram. Patients can have different CYP2C19 genotypes, including functional, defective, or ultra-rapid CYP2C19 alleles. The defective alleles catalyze less formation of propionic acid; the ultra-rapid alleles produce higher levels of propionic acid. ${ }^{16}$ We suggest that the metabolic acidosis in our patient was due to the conversion of citalopram to propionic acid and speculate that he might have been a rapid metabolizer. Accumulation of propionic acid in the blood leads to metabolic acidosis with normal lactate levels and can be toxic to the central nervous system. ${ }^{17}$ Our patient also developed respiratory acidosis, possibly secondary to citalopram overdose. Severe pulmonary edema can cause respiratory acidosis through increased work of breathing and abnormal gas exchange from V/Q matching and shunting. ${ }^{18}$ In addition, the serotonin effects on the central nervous system could cause CNS depression and suppress respiratory drive.

Citalopram overdose can cause seizures and cardiac toxicity, including QT prolongation. ${ }^{2,3}$ Clinical data indicate a positive correlation between high citalopram doses and QT prolongation. ${ }^{3}$ Our patient had QT prolongation with a QTc of $462 \mathrm{~ms}$. He also had altered mental status, lethargy, a 30 second seizure, increased deep tendon reflexes, and rigidity. These neurological manifestations could be secondary to either serotonin syndrome, or effects of propionic acidemia on the central nervous system, or both. ${ }^{17}$ Neurological manifestations of propionic acidemia secondary to disorders of propionate metabolism include, hyperammonemia, lethargy, stroke-like episodes, seizures, and cranial nerve abnormalities. ${ }^{19}$ These associations also support the conclusion that the patient had severe citalopram toxicity.
In summary, citalopram is a safe and effective drug for depression, but life-threatening adverse effects can occur with overdoses. These effects include generalized convulsions, rhabdomyolysis, neurological complications, cardiovascular toxicity, and metabolic acidosis. High doses of citalopram also may cause acute lung injury, acute respiratory distress syndrome, and respiratory failure. These patients usually do well with supportive care. We need more information about propionic acid levels in patients with citalopram overdoses to determine its contribution to the metabolic and clinical presentations.

Author Affiliation: Hawa Edriss is a resident in Internal Medicine at TTUHSC in Lubbock, TX. Marie Pfarr is a medical student in the SOM at TTUHSC in Lubbock, TX.

Received: $10 / 20 / 2013$

Accepted: 10/28/2013

Reviewers: Zachary Mulkey MD, Vaqar Ahmed MD

Published electronically: 01/15/2014

Conflict of Interest Disclosures: None

\section{REFERENCES}

1. Katzung BG, Masters SB, Trevor AJ. Basic and clinical pharmacology. New York; London: McGraw-Hill Medical; 2009.

2. Bin Salih S, Al Qahtani M, Al Anazi T, Al Hussein M, Al Hayyan H, Al Modaimegh H. Metabolic acidosis and generalized seizures secondary to citalopram overdose: a case report. $J$ Clin Pharm Ther 2010; 35(4):479-482.

3. Cooke MJ, Waring WS. Citalopram and cardiac toxicity. European J Clin Pharmacol 2013; 69: 755-60.

4. Hale AS. Citalopram is Safe. British Medical J 1998; 316(7147): 1825 .

5. Personne M, Sjöberg G, Persson H. Citalopram overdose--review of cases treated in Swedish hospitals. J Toxicol Clin Toxicol 1997; 35(3):237-240. 
6. Kelly CA, Upex A, Spencer EP, Flanagan RJ, Bateman DN. Adult respiratory distress syndrome and renal failure associated with citalopram overdose. Hum Exp Toxicol 2003; 22(2):103105.

7. Luchini D, Morabito G, Centini F. Case report of a fatal intoxication by citalopram. Am J Forensic Med Pathol 2005; 26(4):352-354.

8. Jimmink A, Caminada K, Hunfeld NG, Touw DJ. Clinical toxicology of citalopram after acute intoxication with the soledrug or in combination with other drugs: overview of 26 cases. Ther Drug Monit 2008; 30(3):365-71.

9. Person HE, Sjoberg GK, Haines JA, et al. Poisoning severity score grading of acute poisoning. J Toxicol Clin Toxicol 1998; 36:205-213.

10. Ettinger NA, Albin RJ. A review of the respiratory effects of smoking cocaine. Am J Med 1989; 87(6):664-668.

11. Bernard GR, Artigas A, Brigham KL, et al. The AmericanEuropean Consensus Conference on ARDS. Definitions, mechanisms, relevant outcomes, and clinical trial coordination. Am J Respir Crit Care Med 1994; 149(3 Pt 1):818-824.

12. Dahlin KL, Lâstbom L, Blomgren B, Ryrfeldt A. Acute lung failure induced by tricyclic antidepressants. Toxicol Appl Pharmacol 1997; 146: 309-316.

13. Qin L, Zhao D, Xu J, et al. The vascular permeabilizing factors histamine and serotonin induce angiogenesis through TR3/ Nur77 and subsequently truncate it through thrombospondin-1. Blood 2013; 121:2154-2164.

14. Grundemar L, Wohlfart B, Lagerstedt C, Bengtsson F, Eklundh G. Symptoms and signs of severe citalopram overdose. Lancet $1997 ; 349(9065): 1602$.

15. Jimmink A, Caminada K, Hunfeld NGM, Touw DJ. Clinical toxicology of citalopram after acute intoxication with the sole drug or in combination with other drugs: overview of 26 cases. Ther Drug Monit 2008; 30:365-371.

16. Rudberg I, Reubasaet JLE, Hermann M, Refsum H, Molden E. Identification of a novel CYP2C19-mediated metabolic pathway of s-citalopram in vitro. Drug Metab Dispos 2009; 37:23408.

17. Schreiber J, Chapman KA, Summar ML, Ah Mew N, Sutton VR, MacLeod E, Stagni K, Ueda K, Franks J, Island E, Matern D, Peña L, Smith B, Urv T, Venditti C, Chakarapani A, Gropman AL. Neurologic considerations in propionic academia. Mol Genet Metab 2012; 105:10-5.

18. Aberman A, Fulop M. The metabolic and respiratory acidosis of acute pulmonary edema. Ann Intern Med 1972; 76:173-184.

19. Scholl-Bürgi S, Haberlandt E, Gotwald T, Albrecht U, Baumgartner Sigl S, Rauchenzauner M, Rostásy K, Karall D. Stroke-like episodes in propionic acidemia caused by central focal metabolic decompensation. Neuropediatrics 2009; 40:76-81. 